\title{
Service quality of psychiatric care from patients' perspective; a descriptive cross sectional study conducted in National Hospital, Sri Lanka
}

\author{
Wijenayake $\mathbf{P H}^{1}$, Kumarapeli $\mathbf{V}^{2}$, Samarasinghe $\mathbf{Y J}^{3}$, Gunathilake $\mathbf{M D U}^{4}$ \\ ${ }^{\prime}$ Medical Service Unit, ${ }^{2}$ Policy Analysis Unit ${ }^{3}$ Education, Training and Research Unit, ${ }^{4}$ Provincial Director's Office, \\ Western Province, Ministry of Health, Sri Lanka.
}

Correspondence: Dr. Priyasha H.Wijenayake

e-mail: pwijenayake89@yahoo.com

(1) https://orcid.org/0000-0001-7108-772X

\begin{abstract}
Introduction: In Sri Lanka, mental health has been given a low priority, despite one out of ten in population suffering from a mental illness. Most patients are treated and followed up at psychiatric clinics at government hospitals.

Methods: A descriptive cross sectional study was conducted in the psychiatric clinics in the National Hospital, Sri Lanka (NHSL). The objective of the study is to assess the quality of the services provided by the psychiatric clinics from patient's perspective and to identify the factors affecting the quality of the service. A sample of 292 clinic attendees in remission, followed up at the clinics for $=1$ year, were selected using systematic sampling. Perception and expectations on five quality dimensions of SERVQUAL model (tangibles, reliability, responsiveness, assurance and empathy) was assessed using pre-tested, interviewer administered questionnaire with 30 items, on 05 points Likrt's scale.
\end{abstract}

Results: Tangibility dimension scored the highest mean (1.4816) and assurance scored lowest mean (1.1054), for expectations. Responsiveness scored the highest mean (2.9816) and tangibility scored the lowest mean (2.1379) for perceptions. Overall perception mean (2.548) regarding quality of service was higher than over all expectation mean (1.218) with a positive gap (1.2). Perception of tangibility was significantly associated with level of education $(p=0.004)$, ethnicity $(p=0.010)$ and unemployment had a significant impact on dimension empathy $(p=0.03)$.

Conclusions: Perception of the psychiatric services at NHSL was found to be better than their expectation. Even though results showed positive quality gap in relation to patient perspective, most of the facilities should be improved.

Key words: Perception, expectation, service quality, quality gap

\section{Introduction}

World Health Organization stated that "There is no health without mental health." It reflected clearly that mental health is an integral part of health. Around 450 million people are suffering from such conditions around the world (1). Every one in four people will be affected by a mental or neurological disorder any time in their life placing the mental health disorders one of the leading causes for morbidity and disability (2). In South East Asian countries, mental health services lack attention and less invested. Service qualities of the available services are also reported as poor (3). According to the statistics, one out of ten was suffering from a psychiatric illness in Sri Lanka and only 20\% seek treatment (4). A high incidence of child and adolescent mental health problems are also being reported (5). In early 90 s the country was notorious for having the highest suicide rates in the world and the figures reported were 46 per 100,000 for males 
and 19 per 100,000 for females (6). It is reported that 28.8 die from every 100,000 in Sri Lanka far above the global average of 11.4 per 100,000 population (7). Therefore it is very important to provide better service for mentally ill patients.

In the history of mental health services in Sri Lanka, mentally ill patients were housed in a separate asylum which was established by the British (8). At present, it provides inpatient care as well as outpatient medications, follow up care, referring patients for admissions, electro convulsion therapy (ECT) and psychotherapy and counseling care in a massive scale as the National Institute of Mental Health or the only mental hospital in Sri Lanka. In addition to the care provided by the National Institute of Mental Health, 22 out of 25 districts provide inpatient as well as outpatient care (9). Altogether, 86 outpatient clinics and 250 outreached clinics provide the services all over the country (4). Services provided by the clinics include arriving at a diagnosis, ordering investigations ranking from simple blood investigations to complex CT scans, prescribing psychosocial interventions, occupational therapy and rehabilitation care are other services provided.

Service quality is defined in business dictionary as an assessment of how well a delivered service conforms to the client's expectations. Not like product quality, service quality is intangible and is judged by the individuals on the perception of the service (10). According to Grönroos, (11) in order to increase the long term quality of service, the customer expectations should be focused, revealed, and calibrated. There are many models to assess the service quality. Out of them the most popular model for quality assessment is SERVQUAL model which was developed by the Parasuraman et al.

Quality mental health care is a newly prioritized area in the world. The identified issues related to mental health care provision are; lack of awareness about the available facilities among mentally ill patients, reluctant to accept that they are suffering from a mental disorder due to the social stigma, fear of being discriminated at health care settings, poor attitudes towards public health services and thoughts related to privacy and confidentiality (12) in the psychiatry clinics. Therefore it is important to know how the patients feel about the provided care, in order to make improvements in the future. Even though there were studies done to assess the service quality of medical and other clinic setups, data on psychiatric service quality was scarese.

This study was conducted to assess the quality of the services provided by the psychiatric clinics at NHSL from patients' perspective and to identify the factors affecting the quality of the service.

\section{Methods}

A descriptive cross sectional study was conducted at psychiatric clinics of NHSL with quantitative approach. A sample of 292 patients who were being treated at psychiatric clinics was selected for the study through systematic sampling method. The inclusion criteria were as follows: patients who were in remission (was no longer experiencing clinical levels of symptoms related to the original issue) (13), who have been routinely attending the clinics for one year or more and patients who were capable and suitable to give the consent and understand the information were included in the study. The suitability of the patients was decided by the treating psychiatric team. Patients who came in for first visit to the psychiatric clinics (whose diagnoses were not yet established), unplanned visits to the clinics such as those requested to come to review the treatment response after a few days and those who came on a different clinic days than they were assigned to, where the treatment team is different were excluded from the study.

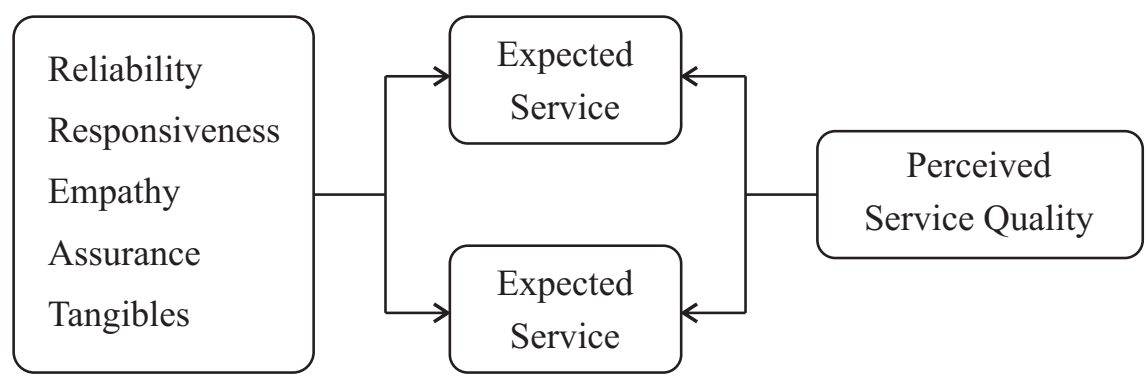

Figure1: Conceptual framework of SERVQUAL model 
A voluntary participation was encouraged throughout the process. Pretested interviewer administered questionnaire was used for data collection. It was prepared referring the SERVQUAL model (14) which was the most commonly used service quality assessment tool in literature. It has been successfully used in health care quality assessments too.

The dimensions of the model were,

1. Reliability - Ability to perform promised service dependably and accurately

2. Responsiveness - Willingness to help and positive prompt service

3. Empathy - Caring and individualized attention that provides

4. Assurance - Knowledge and courtesy of employees and their ability inspire trust and confidence

5. Tangibles - Physical facilities, equipment and appearance

\section{Data collection tool}

Original SERVQUAL questionnaire had 22 statements. Principal investigator used same dimensions but modified and additional items were added to the questionnaire to measure the psychiatry clinic attendees' expectations and the perception regarding service quality. Focus group discussions were held with psychiatric team to determine what and how to set the statements on expectations and perceptions. The questionnaire composed of two parts. While the first part was related to socio demographic data such as age, gender ethnicity etc., second part covered the patients' expectations and perception regarding quality of services provided by the psychiatric clinics of NHSL. Questionnaire was prepared in all three languages; Sinhala, Tamil and English. Ethical and administrative approval was taken to conduct the study. Measures were taken to preserve the privacy, confidentiality and the autonomy. Statistical package for social science (SPSS) version 21 was used to analyse data. The socio demographic profile of the respondents were analyzed and presented in percentages. Mean expectation score and perception score for each dimension were calculated. The gap score was calculated by perception minus expectation scores for each dimension. (12). It was represented in a radar chart.
Two categories of favorable expectations and unfavorable expectations and the two categories of favorable perceptions and the unfavorable perceptions were decided in order to check the positive associations with the independent variables such as gender, ethnicity, age, civil status and current level of employment using the chi-square test. Each positively worded question and the negatively worded question were given 1-5 marks. It was decided that at least 4 out of 5 marks should be obtained for favourable level of expectation and the perception.

\section{Results}

After excluding the non-respondents $(\mathrm{n}=14)$ and questionnaires with incomplete responses $(n=06)$, 272 respondents were included for the analysis. There was almost equal percent of respondents in the 35 - 44 years $(21.7 \%)$ and $45-54$ years $(22.4 \%)$ age groups. Two thirds of the participants were Sinhala $(65.8 \%)$. Out of the participants majority were studied up to grade ten ( $\mathrm{n}=127,45 \%)$. However, only $26.5 \%$, $(\mathrm{n}=72)$ had passed the GCE $\mathrm{O} / \mathrm{L} ; 14.3 \%(\mathrm{n}=38)$ studied up to GCE A/Land $11.3 \%(n=31)$ passed at least one subject of GCE $\mathrm{A} / \mathrm{L}$. there were $3.7 \%$ of basic degree holders. Only $1.5 \%(\mathrm{n}=04)$ of the participants had never been to school. Of the participants, $68.3 \%(n=186)$ were not employed and there were more males $(59.2 \%)$ compared to females $(40.8 \%)$. Approximately, half of the participants, were married $(53.3 \%, \mathrm{n}=145)$ while one third were unmarried $(34.2 \%, \mathrm{n}=93)$. Considerable number of the participants $(29.8 \%, \mathrm{n}=$ 81) were travelling for more than $50 \mathrm{~km}$ to come to the clinic and only $10 \%(\mathrm{n}=27)$ resided less than 10 $\mathrm{km}$ from the NHSL. Main mode of transport of the study sample was by bus $(61 \%, \mathrm{n}=166)$. Some participants had their own vehicles $(18.4 \%)$.

Table 1 shows mean values for each dimension of the SERVQUAL model for patients' expectations. Tangibility scored the highest mean value (1.4816) while assurance scored the lowest value (1.1054).

Responsiveness scored the highest mean value (2.9816) and tangibility scored the lowest mean value (2.1379) for perception (table 2). When compared with the mean values for expectation, tangibles which the respondents expected most were found to receive the least by the respondents. 
Table 1: Mean values for each dimension of the SERVQUAL model for patients' expectation

\begin{tabular}{ll}
\hline Dimension & Mean Value \\
\hline Tangibility & 1.4816 \\
Reliability & 1.1412 \\
Assurance & 1.1054 \\
Responsiveness & 1.1812 \\
Empathy & 1.1820 \\
\hline Total & 6.0914 \\
\hline
\end{tabular}

Table 2: Mean values for each dimension of the SERVQUAL model for patients' perception

\begin{tabular}{ll}
\hline Dimension & Mean Value \\
\hline Tangibility & 2.1379 \\
Reliability & 2.3184 \\
Assurance & 2.8401 \\
Responsiveness & 2.9816 \\
Empathy & 2.4620 \\
\hline Total & 12.74 \\
\hline
\end{tabular}

Assurance which scored the least in terms of expectations received a comparatively better perception.

\section{Analysis of the service quality gap \\ According to the Parasuraman et al (1988),

$$
\begin{aligned}
\text { Service Quality } & =\text { Perception }- \text { Expectation } \\
& =(\mathrm{P}-\mathrm{E})
\end{aligned}
$$

Total mean for perception $\quad=12.74 / 5$

$$
\begin{array}{ll} 
& =2.548 \\
\text { Total mean for expectation } & =6.0914 / 5 \\
& =1.218 \\
\text { Service quality gap score } & =2.548-1.218 \\
& =1.230
\end{array}
$$

A positive quality gap score indicates that the quality of the provided service was better than the respondents' expectation (12) (Figure 2).

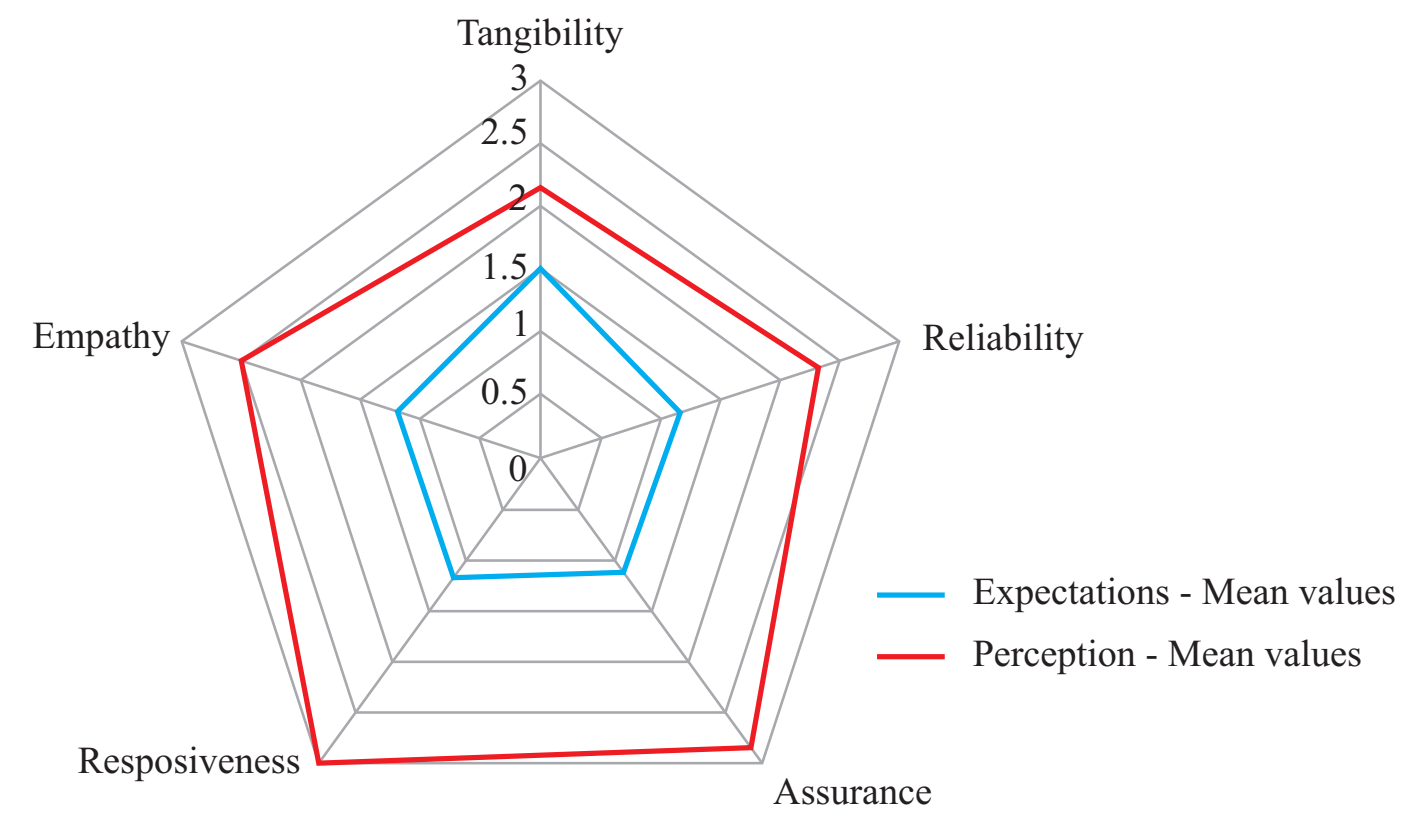

Figure 2: Gap analysis represented in radar chart 


\section{Factors affecting the quality gap}

Analysis of the individual questions in the questionnaire revealed the factors affected for the quality gap. Summary of the factors that affected positively, according to the dimension are given in table 3. Factors of each dimension scored the lowest and contributed least for positive gap are shown in table 4.

Participants with favourable and unfavourable expectations were cross tabulated with age, gender, and civil status, level of education and current level of employment to find out possible associations. Similar analysis was done for participants with favorable and unfavorable perceptions.

None of the other independent factors were positively associated with the dependent variables $(p$ $>0.05)$ studied except level of education $(p=0.015)$, unemployment $(p=0.96)$ and ethnicity $(p=0.06)$.
Perception of tangibility was significantly associated with level of education ( $p=0.05)$, unemployment $(p=0.004)$ and ethnicity $(p=0.010)$. Unemployment had a significant impact on dimension empathy $(p=$ $0.03)$.

When trying to categorize the participants into those with favorable vs unfavorable expectations, all the participants were found to be under the unfavorable level of expectations as per the cut-off used. Therefore, statistical analysis could not be performed for associations with the selected independent variables. Associations could not be done for the overall service quality gap as there were no evidence in the literature regarding this analysis.

Table 3: Summary of the factors affected positively according to the dimension

\begin{tabular}{ll}
\hline $\begin{array}{l}\text { Dimension } \\
\text { Responsiveness }\end{array}$ & $\begin{array}{l}\text { Factors affected positively with highest scores } \\
\text { Patients perceived that the health care providers give prompt } \\
\text { service to the patients attracting their trust }\end{array}$ \\
Reliability & $\begin{array}{l}\text { As all the relevant investigations are ordered at the first visit, } \\
\text { patients don't need to come frequently } \\
\text { Availability of all the essential drugs in the clinics and no need to } \\
\text { purchase from outside pharmacy }\end{array}$ \\
Empathy & $\begin{array}{l}\text { Consultation time is adequate to discuss patients' matters in the clinic } \\
\text { Tangibility }\end{array}$
\end{tabular}

Table 4: Summary of factors least contributed for positive gap according to the dimension

\begin{tabular}{ll}
\hline $\begin{array}{l}\text { Dimension } \\
\text { Tangibility }\end{array}$ & Factors \\
Responsiveness & $\begin{array}{l}\text { Welcome of the staff was poor } \\
\text { e.g. clinic records, books and drugs are not kept in a way of easy access }\end{array}$ \\
Reliability & $\begin{array}{l}\text { All the relevant services such as adding drugs or investigations } \\
\text { depending on the treatment response were not done at one visit. }\end{array}$ \\
Empathy & $\begin{array}{l}\text { Operating hours in the clinics are not convenient for all the patients } \\
\text { Assurance }\end{array}$ \\
\hline
\end{tabular}




\section{Discussion}

Due to the scarcity of studies done on quality assessment of psychiatric services locally, current study was compared with studies done in medical and related clinics. Most of the patients followed up in medical clinics were above the age of $50 \mathrm{yrs}$, females and lived in catchment areas $(<10 \mathrm{~km})$ (15). This study showed that the psychiatric patients were predominantly male as they are the vulnerable group and they can be victim to the illness before reaching the middle age. Majority of the psychiatric patients lived $>50 \mathrm{~km}$ away and travelled to the clinics where they did not stigmatize and were able to get drugs.

A similar study done on attendees to accident and emergency department of Teaching Hospital Kurunegala (16) revealed that the highest score was obtained for tangibility dimension. This score is very much similar to the tangibility score obtained in this study for expectation. It implied that patients' expectation mainly centered on physical facilities and appearance. Assurance scored the lowest score which is also similar to our study (16). The reason may be that in our setup most of the patients do not know that they have a right to know the qualifications and competency of the care giver and they believed that care is always provided by the qualified people.

In the current study responsiveness scored the highest perception, in contrast to the results of the study done at Teaching Hospital Kurunegala (16). It may be due to the fact that most of the staff categories help the psychiatric patients in a sympathetic way without hurry. In this study, it revealed a positive quality gap where patient's expectations were fulfilled. The qualities of the care givers may have contributed to it. In contrast, the study done in Kurunegala (16) reveled negative quality gap for all SERVQUAL dimensions where the expectations of the patients were not met. In our study, the finding of positive quality gap may be due to either patients expected less as they thought that they were marginalized people and discriminated by the society or they perceived more than they expected. Responsiveness was the main contributor for the positive quality gap where they perceived healthcare workers offered prompt service and have won their trust.
Different findings were reveled at Kurunegala where the patients expected health care workers to explain more about the illness and expected the staff to have good hygiene (16).

The study identified that there was significant impact exerted on the perception of the dimension empathy by participants' age, ethnicity, educational level and the current level of employment similar to a study done at five private hospitals in Jaffna showing a significant impact on patient satisfaction by age and level of education (17). Similar study done by Kavitha (18) at Sri Gokulum Hospital, India, highlighted the impact of age and level of education on the quality gap of dimension empathy.

\section{Conclusions}

Patients' highest expectation was for the tangibility dimension which means that patients expected more on physical facilities and they perceived it as unsatisfactory in this clinic setup. Patients perceived that responsiveness of the clinic was high, may be due to doctors and other staff behaved in compassionate way. Patients were not much concerned about the capability and qualifications of the care providers of the clinic as they believed that all the staff categories were well trained and qualified for service delivery through the government clinics. The feeling of being marginalized and discriminated by the society may have contributed to the higher scores in perception than expectation which has contributed to an overall positive quality gap in this study. However, the need to improve the quality of human and physical resources at these settings in order to preserve the dignity and respect of the patients is recommended.

\section{Acknowledgements}

The authors acknowledge all the participants and the staff members of the clinic and all those who have provided valuable ideas for successful conduct of the study.

\section{References}

1. World health Organization, (2016) WHO Mental health action plan. Available at: http//www.who.int/mental Health [Accessed 23rd April]. 
2. World Health Organization, (2013) Mental Health Action Plan 2013-2020.WHO Press, Geneva, Switzerland. 2017].

3. World Health Organization, (2001). World health report 2001- Mental Health: New under-standing, New hope. Available at: http://www.who.int/whr/2001/en/ [Accessed $23^{\text {rd }}$ December 2016].

4. Wipulasena A. (2013) Poor mental health: National Institute can't cope with the demand, Sunday Times, $6^{\text {th }}$ October.

5. Ministry of Health, (2014) mental health action plan (pp. 143-144). In Annual Health Bulletin: Medical statistics unit, Sri Lanka.

6. World Health Assembly, (2012). The global burden of mental disorders and the need for a comprehensive, coordinated response from health and social sectors at the country level.

7. Knipe DWCM, Fernandoo R, Pearson M, Flemming K, Onradson and David Gunnel, (2014) Suicide in Sri Lanka 1975-2012: age, period and cohort analysis of police hospital data Available: https://bmcpublichealth. biomedcentral.com/articles/10.1186/1471-2458-14-839 [Accessed 28/02/17].

8. Harishchandra G. The evolution psychiatric services in Sri Lanka: South Asian Journal of Psychiatry, 2015; 2:1.

9. Ministry of Health. (2015) National mental health programme. In Annual Health Bulletin: Medical statistics unit, Sri Lanka.
10. Parasuraman A, Zeithaml V \& Berry LL. SERVQUAL: A multiple item scale for measuring consumer perception of measuring service quality, Journal of Retailing, 1988; 64(1): 12-40.

11. Gronroos C. A service quality model and its marketing implications, European Journal of Marketing; 1984; 18(4): 36-44.

12. Ellepola Y. (2016). Why Sri Lanka needs better mental health care, CEYLON TODAY, $10^{\text {th }}$ October.

13. Kennady S (2002). Assessing full remission, Journal of psychiatry \& Neuro-Science; 2002; 27: 233-4.

14. Parasuraman A, Zeithaml V \& Berry LL. A conceptual model of service quality \& its implications for further research, Journal of Marketing, 1985; 49: 41-50.

15. Wijemanna WMUS (2011). Quality of service provision patients at medical clinics in secondary care hospitals in the Western province, Post Graduate Institute of Medicine.

16. Samarakoon DS (2014). Study on perceived and expected Quality of services by patients attending accident and emergency unit Provincial General Hospital Kurunegala, Post Graduate Institute of Medicine.

17. Sritharan S \& Velanampy T. ( 2011). Service quality \& customer satisfaction: A study of selected private Hospitals in Jaffna District, Sri Lanka.

18. Kavitha R. Factors influencing the service quality gap between Expectations and perceptions, A study at Sri Gokulum Hospital, International Journal of Business and Management Invention, 2012; 1: pp. 30-36. 